\title{
Experimental Results of the First Two Stages of an Advanced Transonic Core Compressor Under Isolated and Multi-Stage Conditions
}

$$
\text { GT2015-42727 }
$$

Patricia S. Prahst

Zin Technologies, Inc

Cleveland, $\mathrm{OH}, \mathrm{USA}$
Sameer Kulkarni

NASA Glenn Research Center

Cleveland, $\mathrm{OH}$, USA
Ki H. Sohn

The General Electric Company

Cincinnati, $\mathrm{OH}$, USA

ASME Turbo Expo 2015

June 15 - 19, 2015, Montréal, Canada 


\section{Outline}

- Introduction

- Objective

- Facility and Rig Overview

- Results

- Conclusion 
National Aeronautics and Space Administration

\section{Introduction}

\begin{tabular}{|c|c|c|c|}
\hline \multirow{2}{*}{$\begin{array}{c}\text { TECHNOLOGY } \\
\text { BENEFITS* }\end{array}$} & \multicolumn{3}{|c|}{$\begin{array}{c}\text { TECHNOLOGY GENERATIONS } \\
\text { (Technology Readiness Level = 4-6) }\end{array}$} \\
\cline { 2 - 4 } & $\mathrm{N}+1(2015)$ & $\mathrm{N+3}(2025)$ \\
\hline $\begin{array}{c}\text { Noise } \\
\text { (cum margin rel. to Stage 4) }\end{array}$ & $-32 \mathrm{~dB}$ & $-42 \mathrm{~dB}$ & $-80 \%$ \\
\hline $\begin{array}{c}\text { LTO NOx Emissions } \\
\text { (rel. to CAEP 6) }\end{array}$ & $-60 \%$ & $-75 \%$ & $-80 \%$ \\
\hline $\begin{array}{c}\text { Cruise NOx Emissions } \\
\text { (rel. to 2005 best in class) }\end{array}$ & $-55 \%$ & $-70 \%$ & $-60 \%$ \\
\hline $\begin{array}{c}\text { Aircraft Fuel/Energy Consumption } \\
\text { (rel. to 2005 best in class) }\end{array}$ & $-33 \%$ & $-50 \%$ & -2013.1 \\
\hline
\end{tabular}

- Projected benefits once technologies are matured and implemented by industry. Benefits valy by vebicle size and mission. $\mathrm{N}+1$ and $\mathrm{N}+3$ values are referenced to a 737-800 with CFM56-7B engines, $N+2$ values are referenced to a $777-200$ with GE90 engines

** ERA's time-phased approach includes advancing "long-pole" technologies to TRL 6 by 2015

$\ddagger \mathrm{CO} 2$ emission benefits dependent on life-cycle CO2e per MJ for fuel and/or energy source used

- NASA Environmentally Responsible Aviation Project (ERA) goal: Identify and mature technologies that together can simultaneously meet the metrics above (noise, emissions, and fuel burn) in the $\mathrm{N}+2$ timeframe

- ERA system studies have shown potential for up to $2.5 \%$ reduction in Thrust Specific Fuel Consumption by increasing core compressor pressure ratio by $30 \%$ 


\section{Introduction}

- Increased loading of the core compressor introduces aerodynamic losses and decreased efficiency in the front stages

- NASA partnered with General Electric to test the front stages of a legacy advanced, highly loaded, transonic core compressor to identify loss mechanisms

- Previous test experience of a compressor which included these front stages indicated a performance deficit relative to design at high speed which was not captured by RANS/URANS CFD 


\section{Introduction}

- Potential explanations of the previously measured performance deficit:

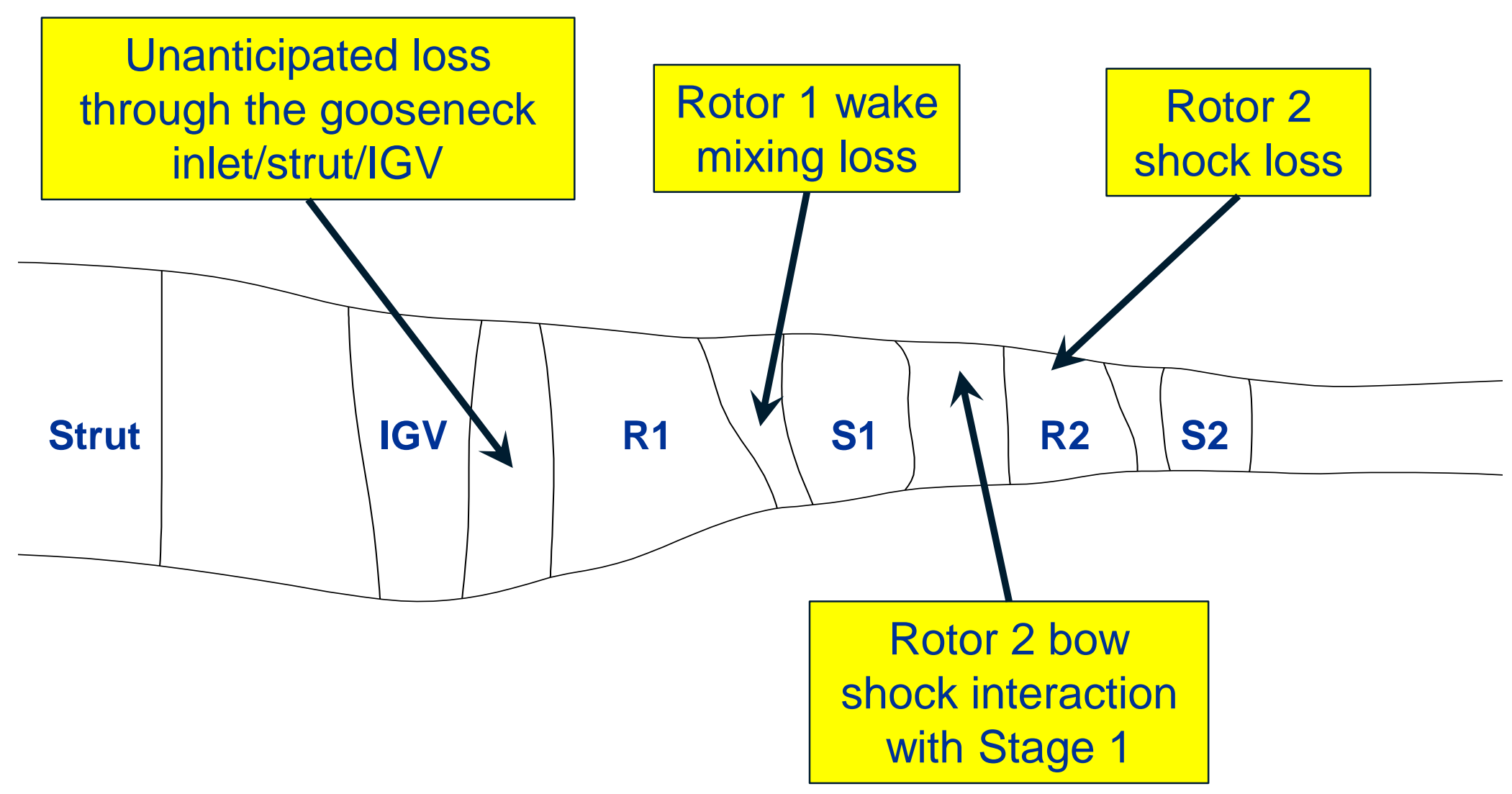


National Aeronautics and Space Administration

\section{Objective}

- Document high-speed performance of a highly loaded front block core compressor under isolated and multi-stage conditions to understand any differences

- Provide detailed aero data for CFD validation

- Rig was operated in 1-stage and 2-stage configurations in separate tests to isolate the effect of the Rotor 2 bow shock on Stage 1
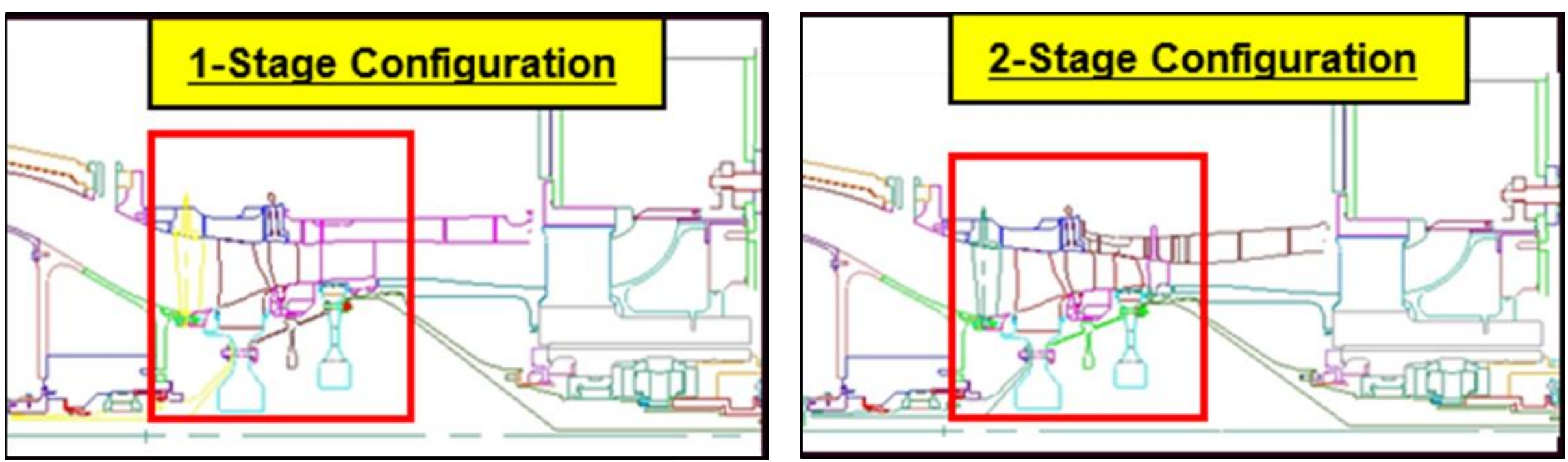


\section{Facility and Rig Overview}

- Testing was conducted at NASA Glenn Research Center in the W-7 High Speed Multi-Stage Axial Compressor Facility

- Atmospheric inlet and exhaust were used during testing

- ESP data acquisition system for steady state pressures up to 150 PSIA

- ESCORT data recording system to obtain and display steady state parameters

- GE supplied proprietary data acquisition and probe actuation systems were used for traversing probe data, dynamic pressure data, and rotor tip clearance measurements.

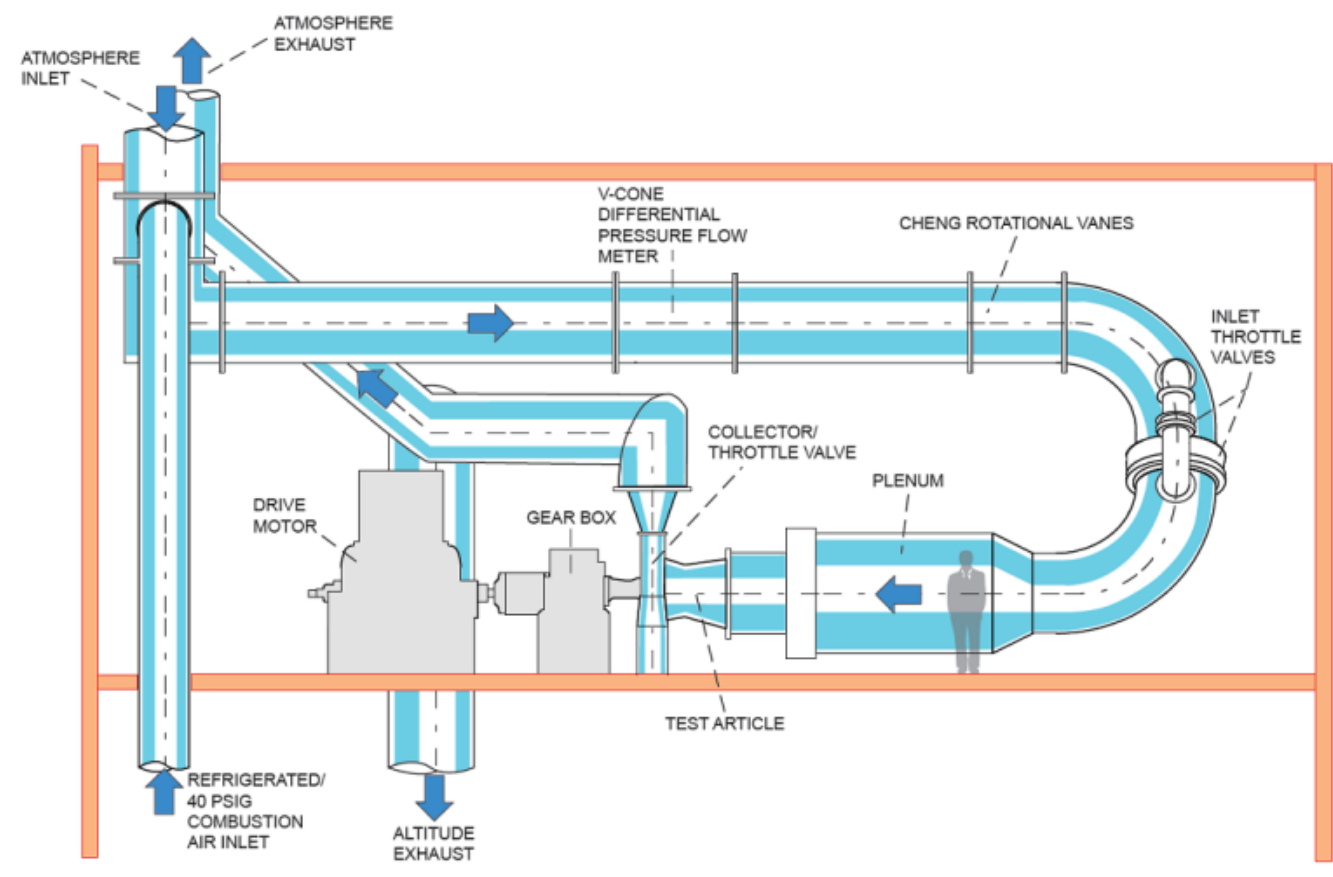

\begin{tabular}{|c|c|}
\hline \multicolumn{2}{|c|}{ W-7 Facility Capabilities } \\
\hline Parameter & Operating value \\
\hline Inlet air pressure & atm to $20 \mathrm{psig}$ \\
\hline Inlet airflow & $10-100 \mathrm{lb}_{\mathrm{m}} / \mathrm{s}$ \\
\hline Atmospheric exhaust & $0.8 \mathrm{psid}$ blowers \\
\hline Altitude exhaust & $26 \mathrm{in} . \mathrm{Hg}$ (vacuum) \\
\hline Rotor speed & $0-18,700 \pm 0.5 \mathrm{rpm}$ \\
\hline Rotor size & 20 to $22 \mathrm{in}$. \\
\hline Drive motor & $15,000 \mathrm{hp}$ \\
\hline
\end{tabular}




\section{Facility and Rig Overview}

- 1-stage configuration

- Strut, IGV, Rotor 1, Stator 1, de-swirl vane

- 2-stage configuration

- Strut, IGV, Rotor 1, Stator 1, Rotor 2, Stator 2

- IGV, Stator 1, and Stator 2 are variable stagger vanes

- Data was acquired at off-schedule vane angles but the current work is focused on nominal vane settings
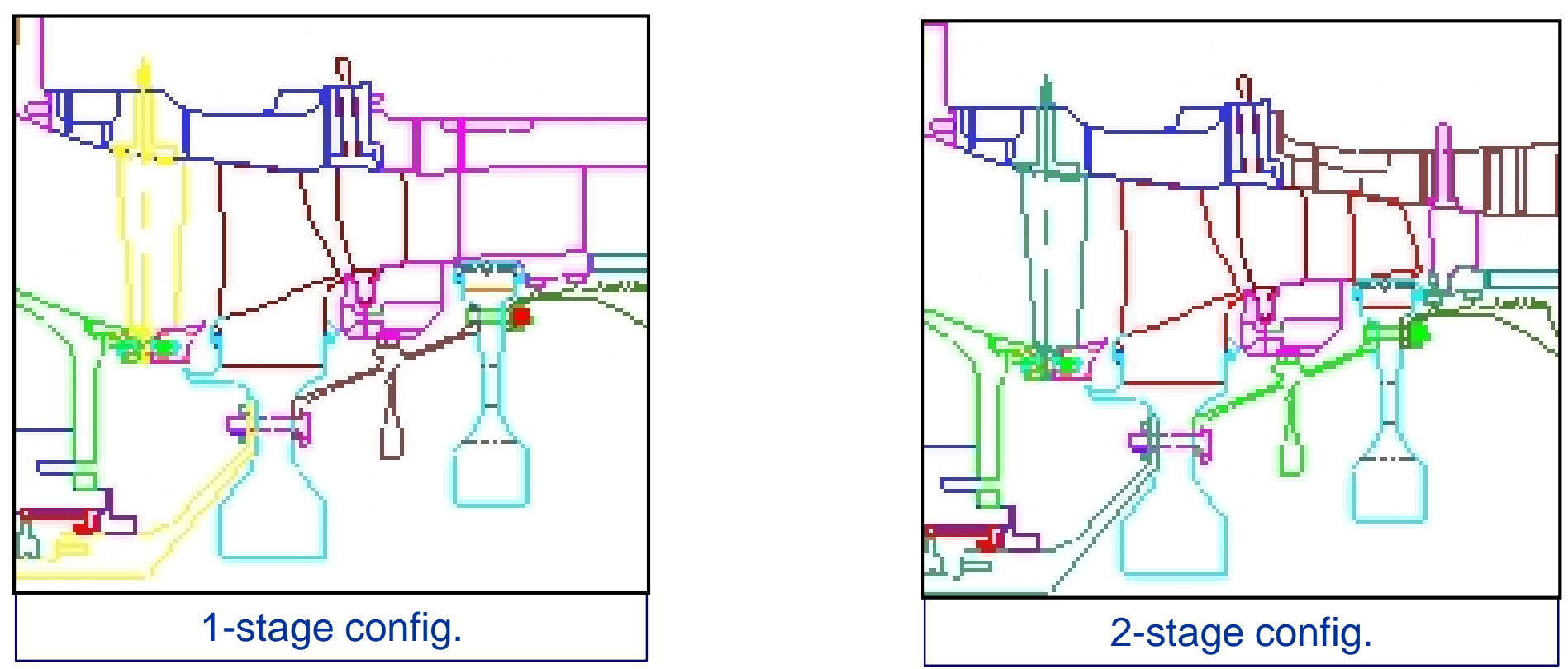


\section{Facility and Rig Overview}

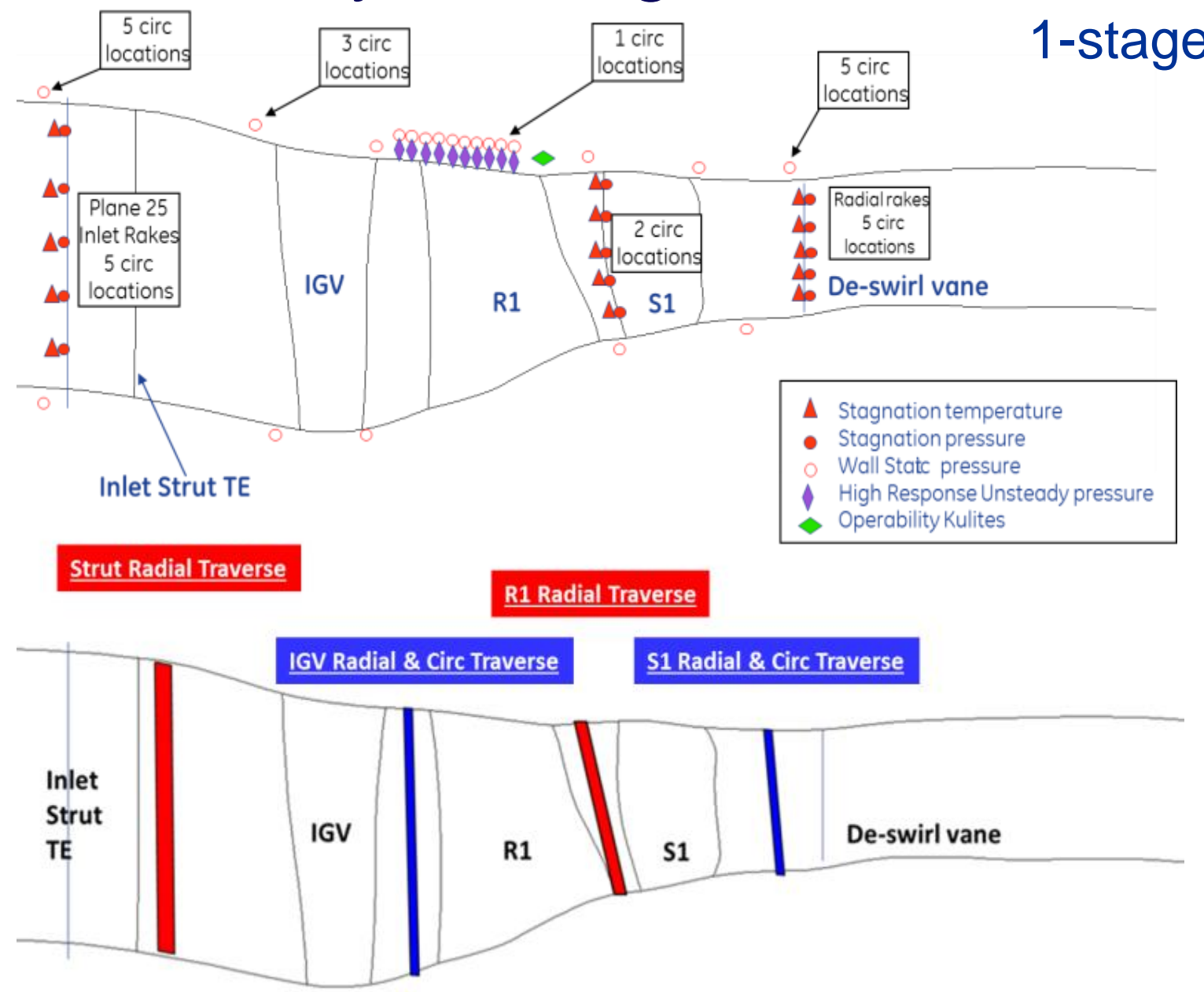

- Inlet and Exit Rakes: 5 circumferential positions with 5 radial locations

- Vane Leading Edges: 2 vanes/stage with P0 probes, 2 vanes/stage with T0 probes at 5 radial locations

- Casing and hub static pressures along the flow path

- Detailed traverses at 4 positions shown above: 5-hole probe, Kulite, hot wire 


\section{Facility and Rig Overview}

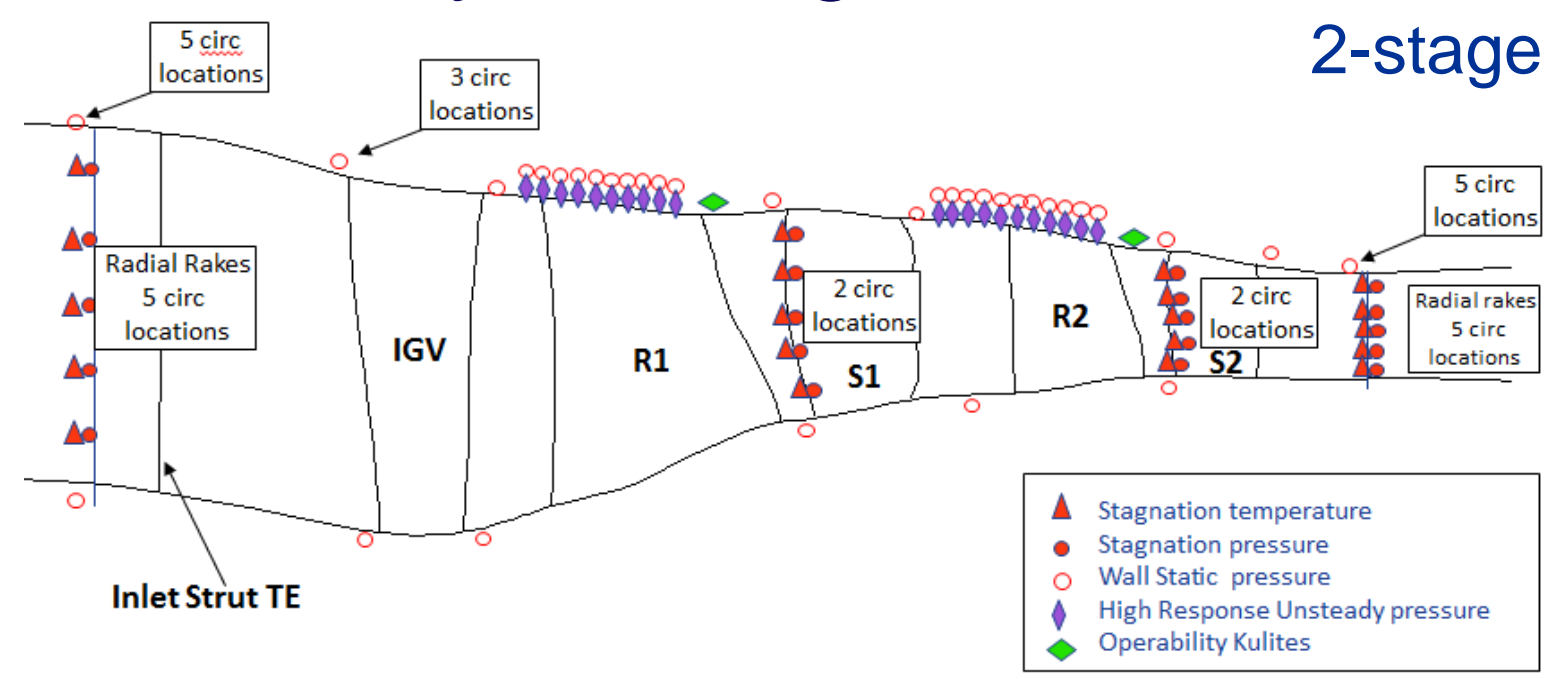

\section{n}




\section{Results: Inlet P0 Profile}

- Inlet total pressure profile aft of inlet screen (within strut passage) below was typical for all run conditions

- Radial-circumferential 5-hole probe survey characterizing IGV wake (black) and strut+IGV wake (red) is shown below

- These data ruled out unanticipated loss due to inlet conditions

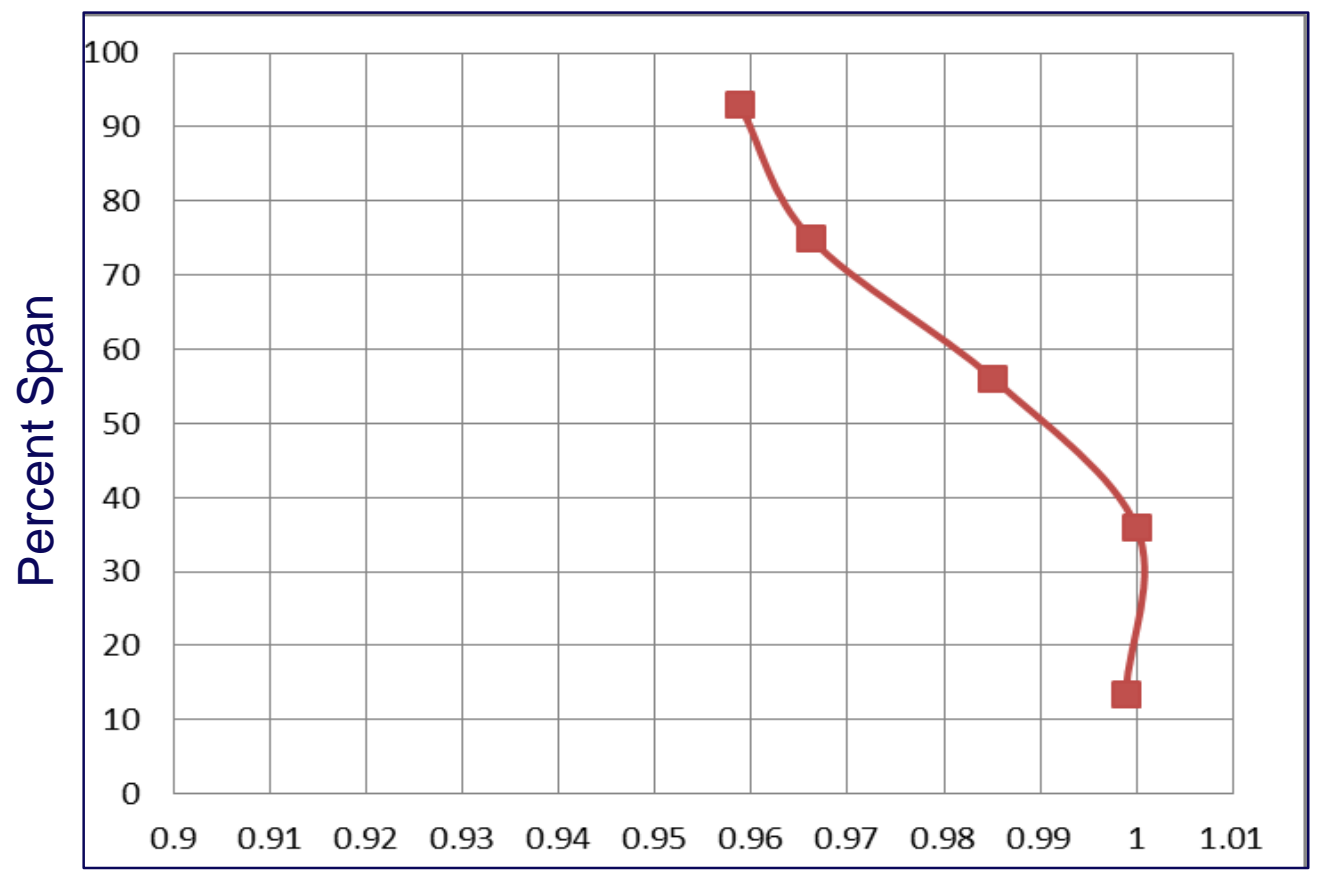

Normalized Inlet Total Pressure

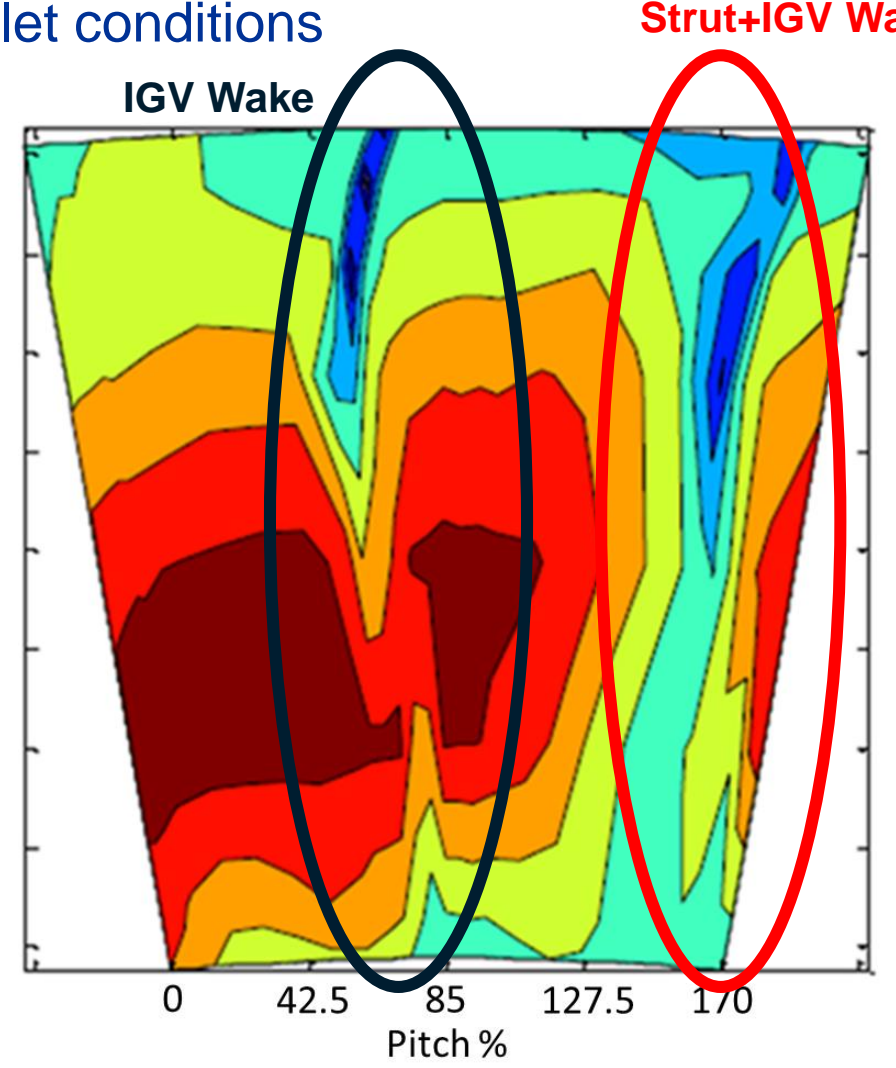


National Aeronautics and Space Administration

\section{Results: 97\% Nc Speedlines}

1-stage configuration

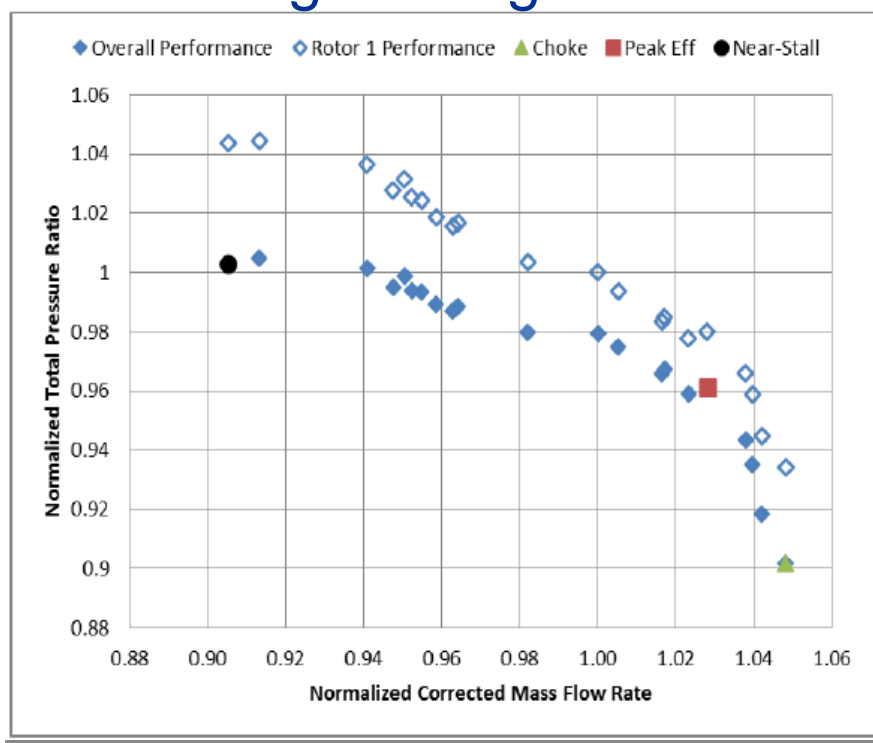

$\bullet$ Overall Performance $\diamond$ Rotor 1 Performance $\Delta$ Choke $\quad$ Peaf Eff $\bullet$ Near-Stall

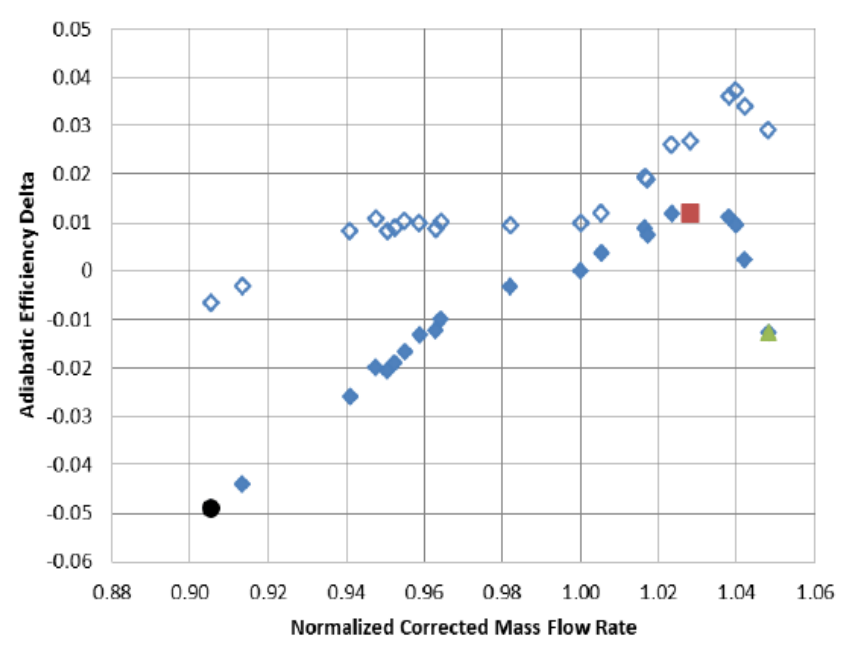

2-stage configuration
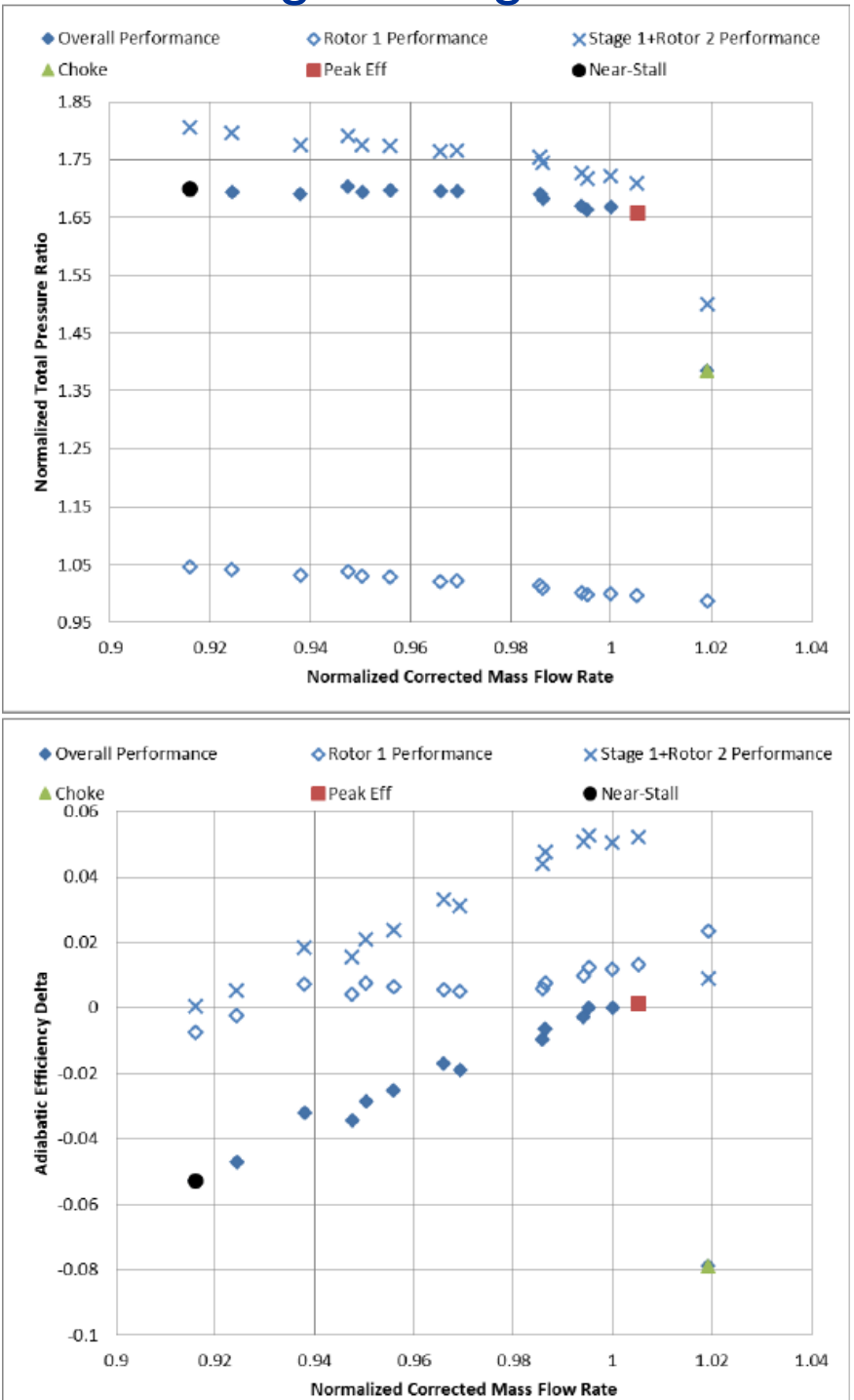


\section{Results: Choke}
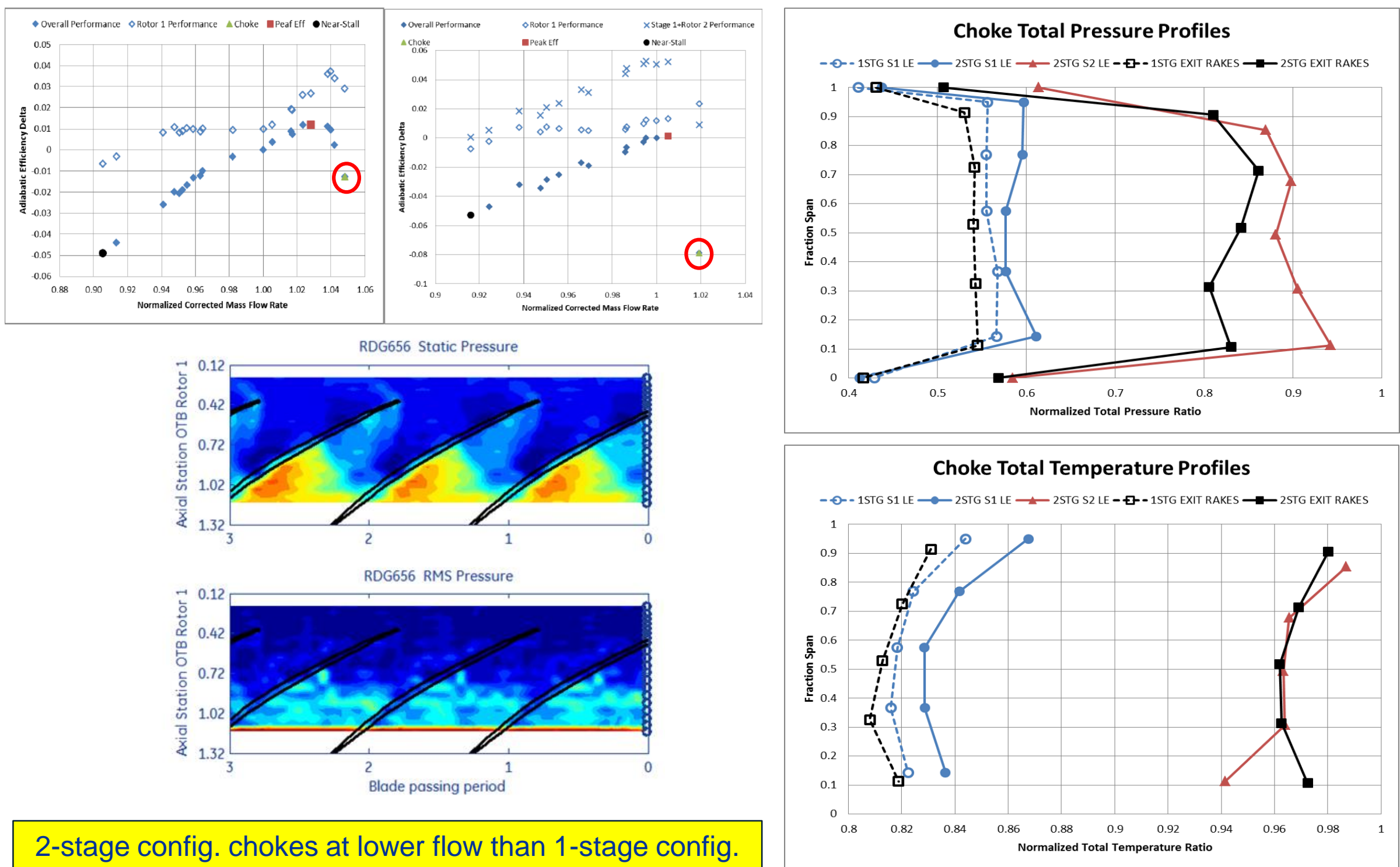

2-stage config. chokes at lower flow than 1-stage config. 


\section{Results: Peak Efficiency}
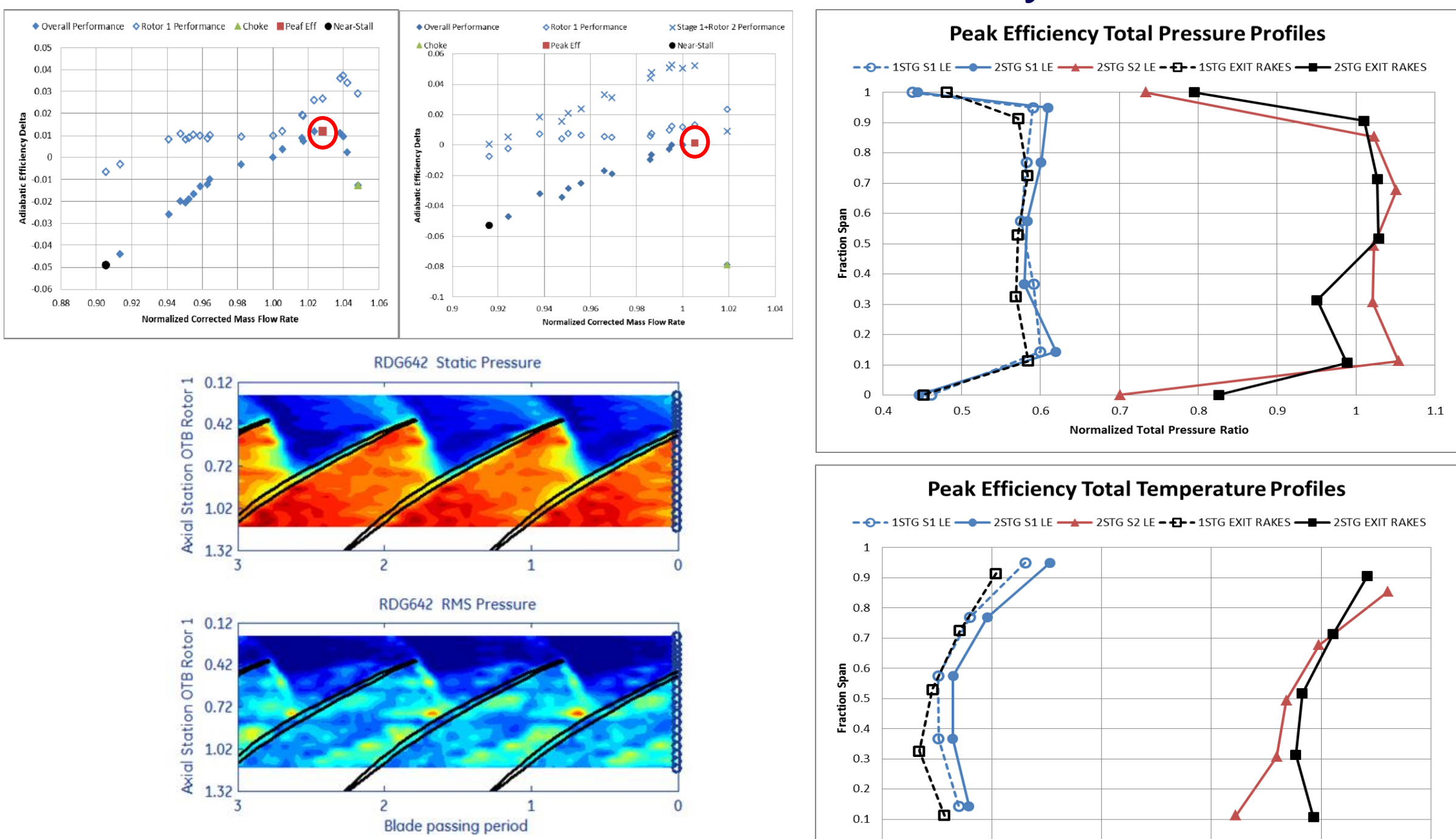

Rotor 1 throttled past peak efficiency in 2-stage config.

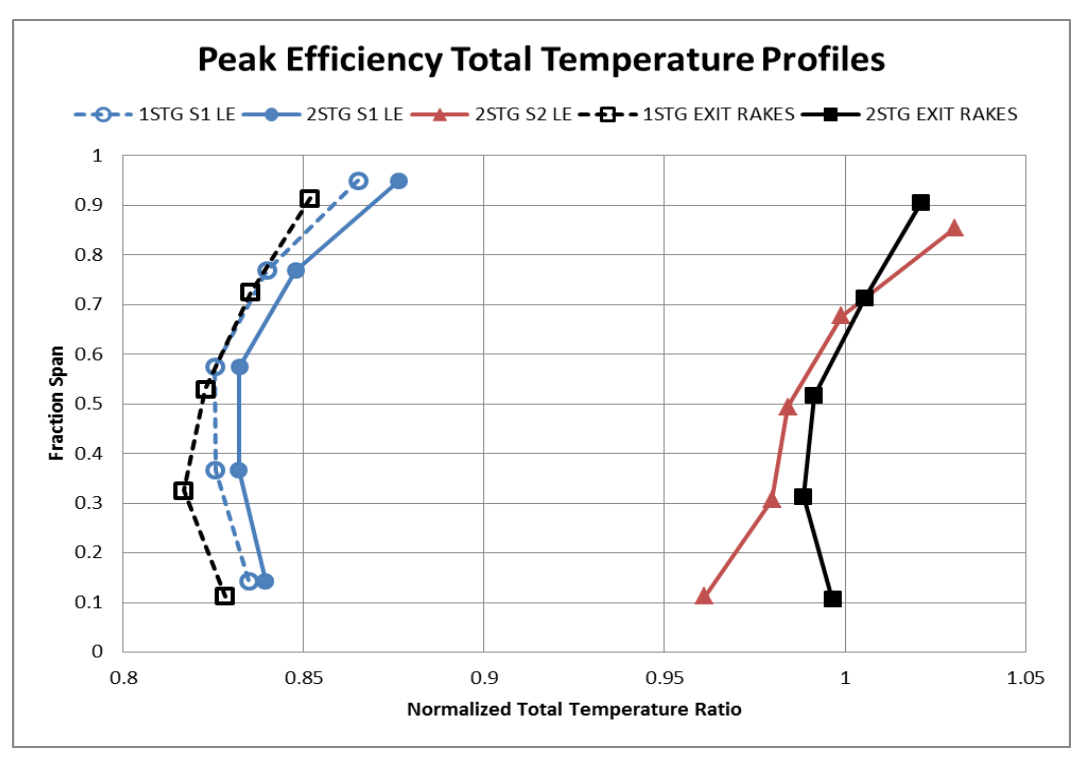




\section{Results: Near-Stall}
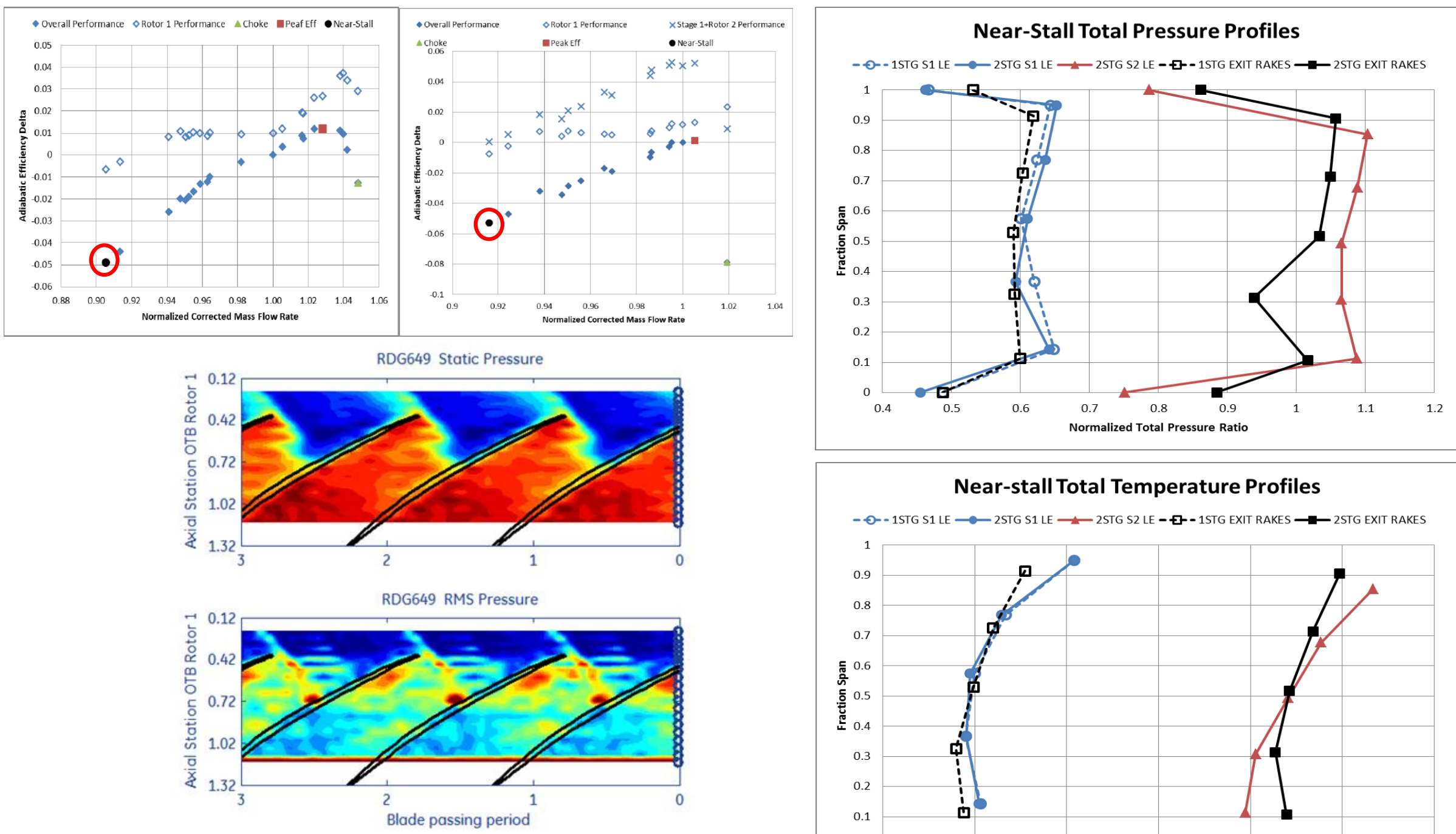

Stage 2 stalls before Stage 1

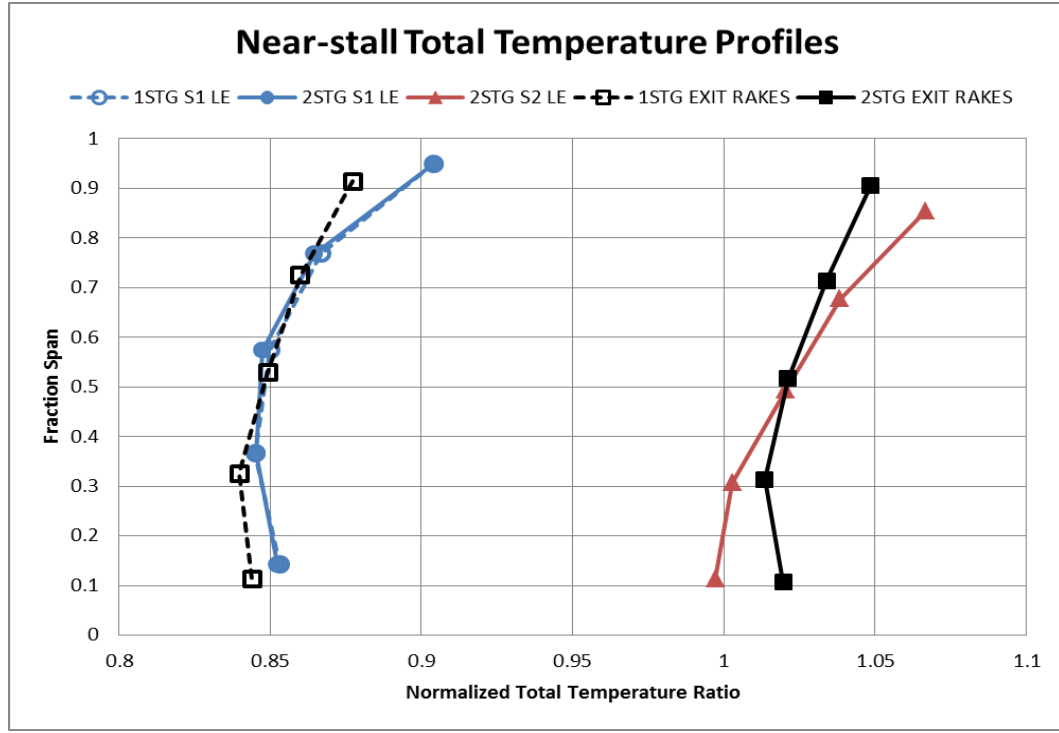




\section{Results: Rotor 1 Performance}

- 2-stage config. choked at lower flow than 1-stage config.

- Rotor 1 does not reach peak efficiency in 2-stage config.

- Negligible change in Rotor 1 performance between 1-stage and 2-stage configs.

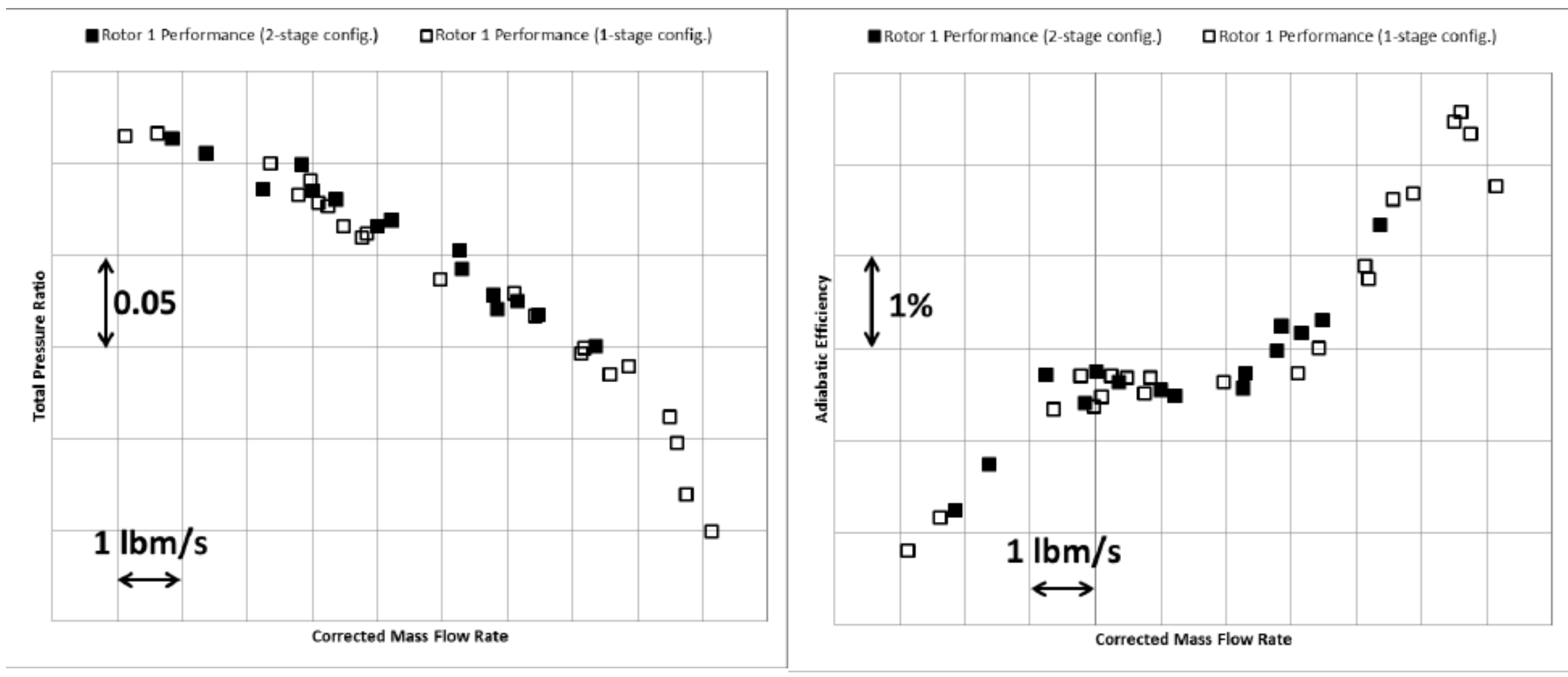




\section{Results: 5-Hole Probe Traverse Aft Stator 1}
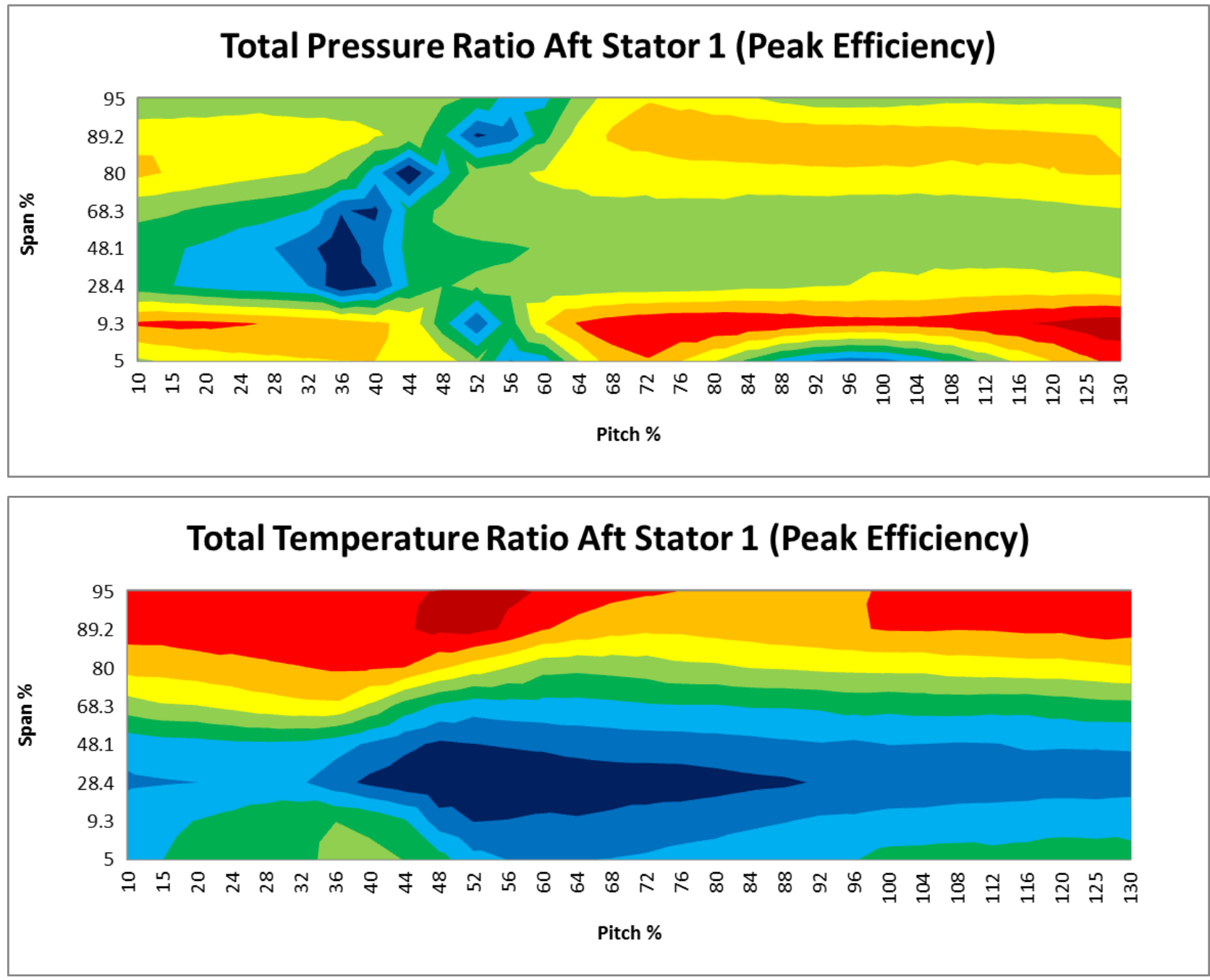

- Stage 1 efficiency (1-stage config.) is low relative to design intent 


\section{Conclusion}

- Data collected upstream of Rotor 1 did not indicate sources of unanticipated loss

- Stage 2 choked at a mass flow rate which prevented Stage 1 from reaching its peak efficiency point, causing a stage mismatch

- Level of Rotor 1 performance is otherwise unaffected by presence of the Stage 2

- i.e. Losses due to Rotor 2 shock loss or bow shock interaction with Stage 1 is unlikely

- Stage 1 performance is down relative to design intent 
National Aeronautics and Space Administration

\section{Following Papers}

- GT2015-42526: Lurie and Breeze-Stringfellow present GE interpretation of the data at the 1-stage peak efficiency point

- GT2015-43389: Hah presents LES results of the 1-stage configuration 


\section{Backup Slides}




\section{Over Rotor Tip Pressure Blocks}
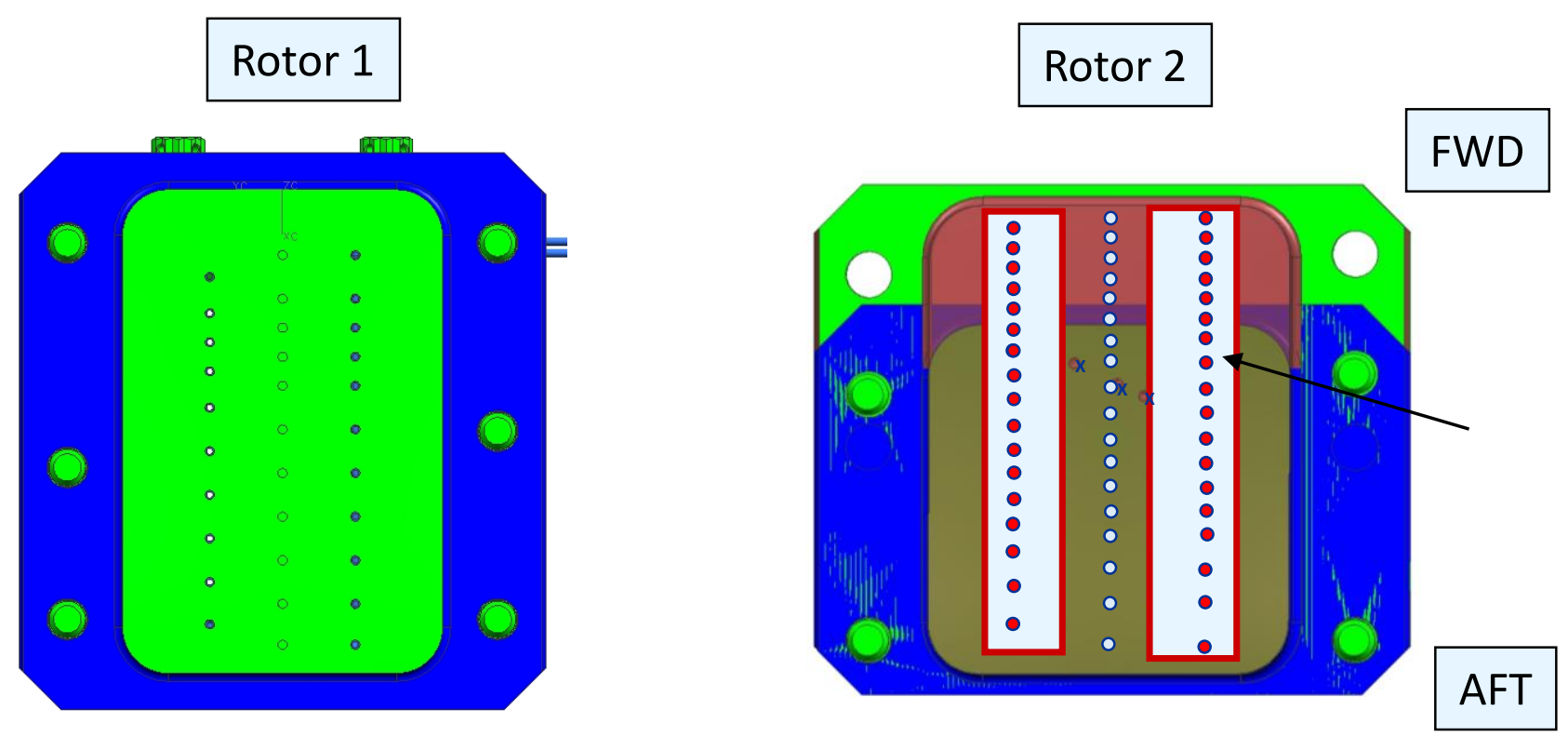

Top case inside looking up 